'Departamento de Imágenes, Clínica Alemana de Santiago. Facultad de Medicina, Clínica Alemana Universidad del Desarrollo. Santiago, Chile. ${ }^{2}$ Residente Radiología, Facultad de Medicina, Clínica Alemana Universidad del Desarrollo. Santiago, Chile.

2Departamento de Anatomía Patológica, Clínica Alemana de Santiago. Santiago, Chile. aResidente Radiología, Facultad de Medicina, Clínica Alemana Universidad del Desarrollo. Santiago, Chile.

Los Autores declaran no tener conflictos de interés. Trabajo no recibió financiamiento.

Recibido el 18 de febrero de 2018, aceptado el 25 de octubre de 2018.

Correspondencia a: Dra. Ema Leal Martínez dra.ema.leal@gmail.com

\section{Presentación atípica de neoplasia pulmonar: lesiones quísticas pulmonares "no siempre benignas"}

\author{
JUAN CARLOS DÍAZ PATIÑO일 JULIA ALEGRÍA BOBADILLA ${ }^{1}$, \\ EMA LEAL MARTÍNEZ ${ }^{2, a}$, YUMAY PIRES ${ }^{2}$, GUILLERMO CHONG MEDEL ${ }^{1}$, \\ CLAUDIO SILVA FUENTE-ALBA ${ }^{1}$, G. CRISTÓBAL RAMOS GÓMEZ

\section{Lung cancer presenting as cystic lesions. Report of eight cases}

Background: Pulmonary cystic nodules are a relatively frequent finding in chest computed tomography (CT). There is a possible association between this finding and lung cancer. Aim: To report eight patients with malignant lung cystic lesions. Material and Methods: Retrospective analysis of images in a CT database from 2007 to 2015, looking for cystic lesions of the lung with wall thickening, whose pathological diagnosis was lung cancer. Results: We identified eight patients with cystic nodules aged 44 to 77 years, of which five were women. Six were active and two former smokers. The pathological diagnosis was adenocarcinoma in seven cases and squamous cell in one. The mean diameter of the cystic lesions was $11.5 \mathrm{~mm}$. The mean diagnostic delay time was 871 days (range 0-1592). The main finding was a gradual thickening of the nodule walls. Conclusions: The presentation of lung cancer as cystic nodules is uncommon. In this series, the change in morphology due to a thickening of the walls with or without a diameter increase, was the clue for the diagnosis.

(Rev Med Chile 2018; 146: 1102-1111)

Key words: Lung Neoplasms; Multiple Pulmonary Nodules; Tomography; $X$-Ray Computed.

\section{L} a alta disponibilidad de tomografía computada (TC) y su uso cada vez más frecuente en el estudio de patología broncopulmonar, ha derivado en un incremento significativo del número de nódulos pulmonares como hallazgo incidental. La mayoría de estos nódulos requieren control, transformándose en un problema desde el punto de vista del manejo por la mayor carga de radiación para los pacientes, el aumento de los costos para las entidades prestadoras de salud y la carga asistencial para los servicios de radiología ${ }^{1}$.

Los datos aportados por los programas de detección precoz de cáncer pulmonar han favorecido el desarrollo de guías que permiten un enfrentamiento más racional de estas lesiones, con énfasis en la reducción del número de controles y falsos positivos de cáncer pulmonar, en desme- dro de la atención hacia los falsos negativos, que en un porcentaje importante se presentan como formas atípicas, no nodulares ${ }^{2}$. Entre estas presentaciones atípicas de cáncer pulmonar se describe el engrosamiento progresivo de las paredes de formaciones quísticas con contenido aéreo o de áreas de enfisema ${ }^{3,4}$.

El objetivo principal de este trabajo es alertar a la comunidad médica y radiológica sobre este signo como manifestación precoz de cáncer pulmonar y como objetivos específicos: 1) describir las características morfológicas de los cánceres pulmonares asociados a espacios quísticos aéreos; 2) evaluar sus posibles modificaciones en el tiempo y el retardo en interpretar esos cambios como sospechosos de lesión neoplásica; 3) describir su comportamiento con PET CT. 


\section{Materiales y Métodos}

Análisis retrospectivo de base de datos de TC de Tórax desde enero del año 2007 hasta diciembre de 2015 en Clínica Alemana de Santiago, de lesiones quísticas pulmonares con engrosamiento de sus paredes, cuyo diagnóstico histopatológico fue cáncer pulmonar, aprobado por el comité de etica de nuesta institución. El diagnóstico de cáncer se basó en análisis histológico (biopsia quirúrgica o transbronquial). La etapificación del tumor se basó en los hallazgos clínicos y patológicos. Para la definición de $\mathrm{T}$, se consideró el diámetro de la totalidad de la lesión incluyendo el componente sólido y quístico.

Los estudios tomográficos fueron realizados en tomografos computados Siemens Definition AS+ de 128 detectores y Toshiba Aquilion One de 320 detectores, el grosor de corte obtenido fue de 1 mm o menor, con $120 \mathrm{kV} \mathrm{y} 150$ mAs ref, pitch 1 .

Las imágenes de los casos identificados fueron reanalizados por dos radiólogos de tórax en forma independiente, con 20 y 10 años de experiencia, visualizados en sistema IMPAX ${ }^{\circledR}$ versión 6.5 en planos axiales y reconstrucciones en múltiples planos, categorizando los siguientes elementos: lóbulo comprometido, localización en el plano axial (adosado a la pleural, periférico no adosado, intraparenquimatosa), diámetro mayor del quiste o área de enfisema, diámetro mayor del nódulo sólido o no sólido (si estaba presente), grosor de la pared quística y el porcentaje de la circunferencia comprometida expresado en grados, mediante método descrito por Farooqui ${ }^{3}$. Este último parámetro se estimó considerando el quiste como una esfera de reloj en el que cada hora representó $30^{\circ}$ (por ejemplo, engrosamiento en la posición dos se le asignaría $60^{\circ}$ ). Además se caracterizó el parénquima pulmonar identificando presencia, tipo y severidad del enfisema pulmonar, presencia o ausencia de otras formaciones quísticas, y presencia de enfermedad intersticial, bronquiectasias o fibrosis (Figura 1).

Para describir las características morfológicas de las lesiones quísticas se usó la clasificación de Mascalchi (Figura 2) ${ }^{4}$. El tipo I corresponde a
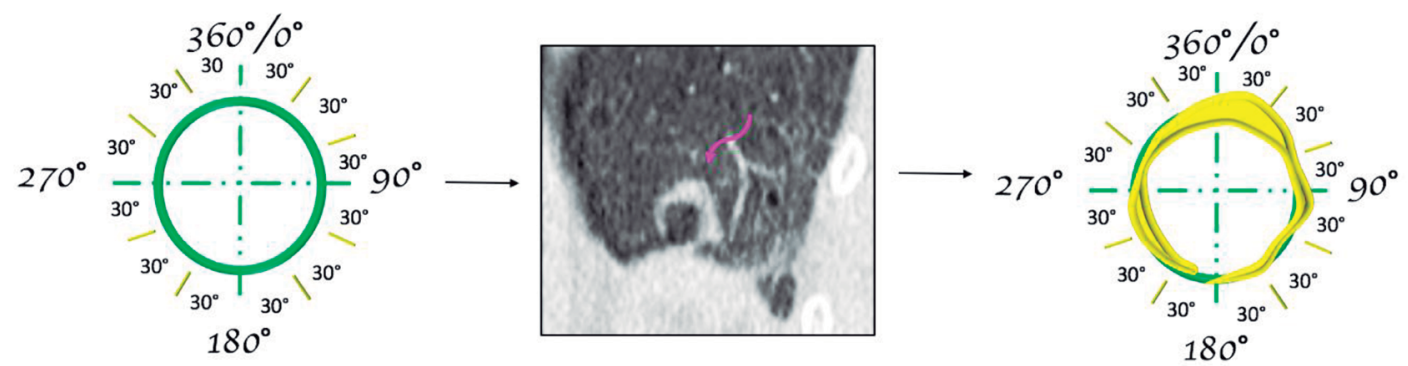

Figura 1. Ejemplo de la clasificación de Farooqui, que es el porcentaje de la circunferencia comprometida de la pared del nódulo expresada en grados. En el ejemplo $360^{\circ}$.

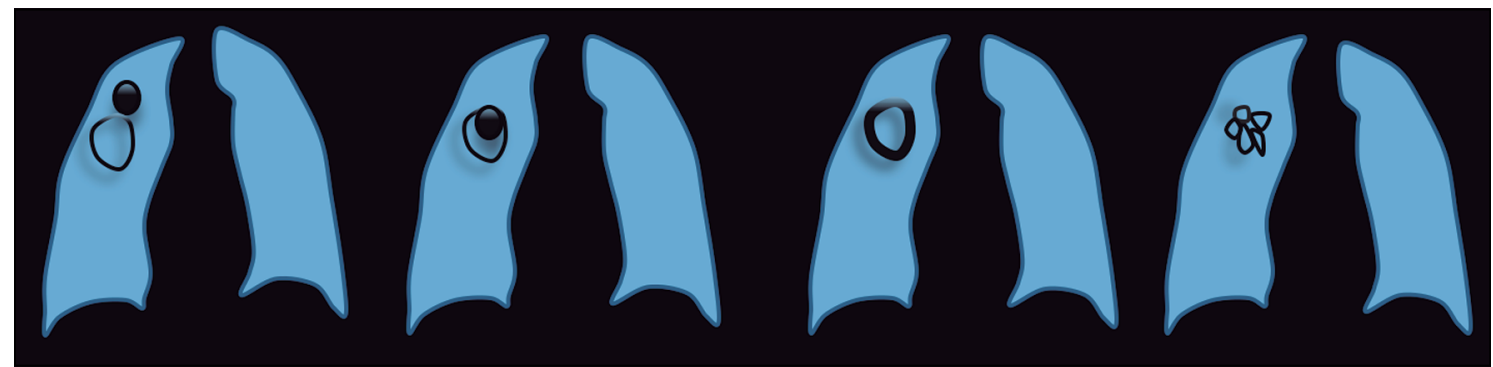

Figura 2. Adaptación de la Clasificación Mascalchi. Cuatro Patrones morfológicos asociados a espacios quísticos. Tipo I: Corresponde a opacidad que sobresale de la pared del nódulo. Tipo II: opacidad confinada al nódulo quístico. Tipo III: Densidad de partes blandas que se extiende por la pared del nódulo y Tipo IV: Nódulo con múltiples tabiques y/o racimos dentro del quiste. 
una densidad de partes blandas (nodular o no nodular), protruyendo desde la pared del quiste; el tipo II corresponde a una densidad de partes blandas (nodular o no nodular) dentro del lumen del quiste; el tipo III corresponde a tejido con densidad de partes blandas extendiéndose por toda la pared del quiste y el tipo IV corresponde a tejido de partes blandas entre múltiples espacios quísticos. Dado que en algunos casos la morfología de la lesión cambió en el tiempo, para efectos de la clasificación, se consideró el examen que mostró alteraciones por primera vez. Las lesiones que en el primer control aparecían como quistes de paredes finas $(<2 \mathrm{~mm})$ y sin nódulo, se clasificaron como categoría tipo 0 . En aquellos casos en que las lesiones compartieran características de más de un tipo, los dos radiólogos decidieron por consenso el tipo predominante.

En aquellos casos con estudios de seguimiento, se evaluaron los cambios de tamaño de los quistes y del patrón morfológico.

Las imágenes de PET/CT se evaluaron por un radiólogo con dedidación a PET/CT el que cuantificó la captación de ${ }^{18} \mathrm{~F}-\mathrm{FDG}$ y las clasificó de acuerdo al SUVmax en: captación ausente, leve (SUV max menor o igual a 3), moderada (SUV max mayor de 3 pero menor a 5) y marcada (SUV $\max$ mayor a 5$)^{4}$.

Se consignó además los siguientes antecedentes: hábito tabáquico, motivo de la solicitud de la tomografía computada y el reporte de la lesión en el examen en que aparece por primera vez el engrosamiento parietal. Los informes de las lesiones quísticas que mostraban engrosamiento de su pared (nodular o difuso) se clasificaron en
1) no descrito; 2) benigna: aquella lesión descrita y concluida como benigna y aquella descrita pero considerada no significativa y por lo tanto no consignada en la conclusión; 3 ) sospechoso de malignidad o al menos con necesidad de control. En los casos en que se contó con una serie de exámenes, se consignó el tiempo de "retardo" del diagnóstico" definido como el intervalo de tiempo entre la primera TC que mostró engrosamiento de la pared y la TC que fue informada como lesión con necesidad de control o sospechosa de neoplasia.

\section{Resultados}

Se identificaron ocho pacientes con cáncer pulmonar en relación a espacios aéreos quísticos, de los cuales cinco fueron mujeres. La mediana de edad al momento de la pesquisa de la lesión fue de 65 años (rango intercuartil: 58-71). El antecedente de tabaquismo estaba presente en todos los pacientes, seis activos, uno detenido hace un año y el otro detenido hace más de 30 años. Siete de los ocho pacientes presentaban enfisema pulmonar, dos de ellos avanzado. El diagnóstico histológico fue adenocarcinoma en siete casos y escamocelular en uno. En tres pacientes fue un hallazgo incidental en TC solicitada por patología vascular (dos por sospecha de tromboembolía pulmonar y uno por estudio de aorta) (Tabla 1, Figuras 3, 10).

El diámetro promedio de las lesiones quísticas fue de 11,5 mm (rango 0-23 mm). Se encontraron cinco patrones morfológicos: tipo I, con densidad externa a la pared (tres) (Figura 5), tipo II con densidad interna, uno (Figura 8), tipo III con

Tabla 1. Antecedentes clínicos de los pacientes con cáncer pulmonar en relación a espacios aéreos quísticos

\begin{tabular}{|lcclll|}
\hline & Sexo & Edad & Tabaquismo & Motivo examen & Biopsia \\
Pac 1 & F & 58 & Crónico activo & Control tabaquismo & Adenocarcinoma \\
Pac 2 & F & 58 & Crónico activo & Sospecha TEP & Adenocarcinoma \\
Pac 3 & F & 72 & Crónico detenido hace 32 años & Adenopatía supraclavicular & Adenocarcinoma \\
Pac 4 & F & 44 & Crónico activo & Sospecha TEP & Adenocarcinoma \\
Pac 5 & M & 71 & Crónico activo & Estudio Aorta & Adenocarcinoma \\
Pac 6 & M & 68 & Crónico activo & Control cáncer pulmonar & Escamoso \\
Pac 7 & F & 77 & Crónico suspendido hace 1 año & Sospecha de neumonia en Rx & Adenocarcinoma \\
Pac 8 & M & 61 & Crónico activo & Estudio Enfisema & Adenocarcinoma \\
\hline
\end{tabular}



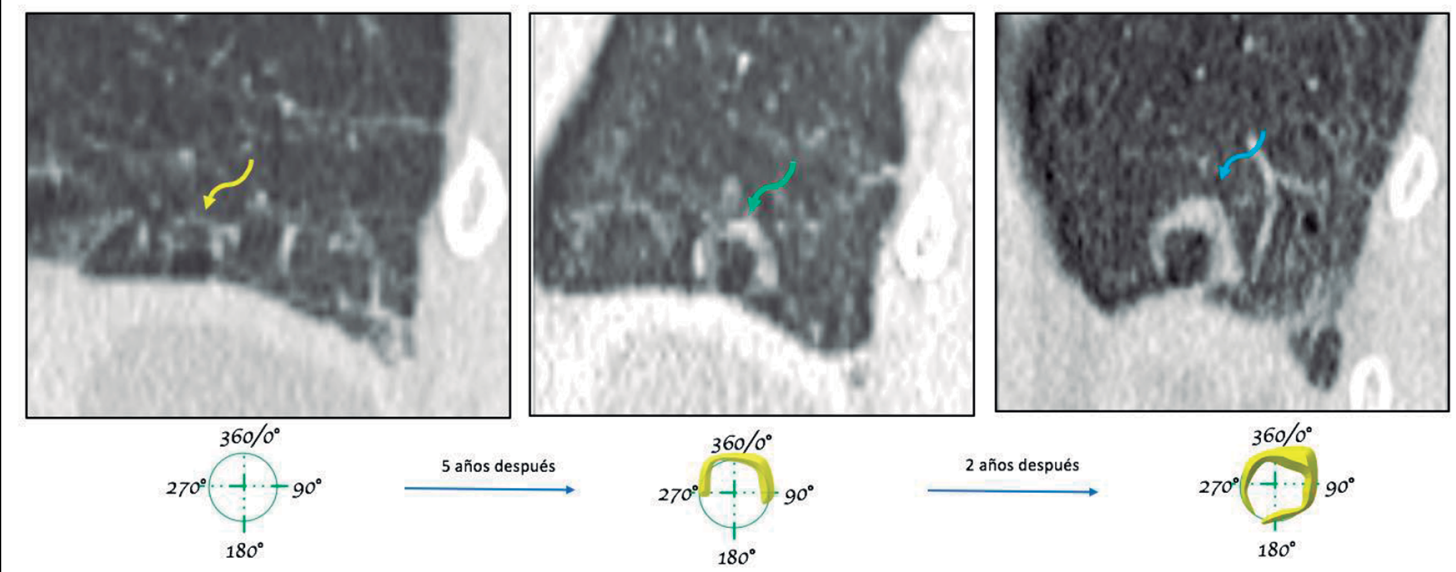

Figura 3. Caso 1. Patrón tipo III. Mujer de 58 años con tabaquismo crónico activo y enfisema avanzado. Se realiza tomografías computadas periódicas por su tabaquismo. En la primera tomografía computada se observa pequeña formación quística aérea de pared, casi imperceptible en la base del lóbulo inferior izquierdo, indistinguible de otras imágenes de enfisema adyacentes (flecha amarilla). En control posterior 5 años más tarde, el grosor de la pared y el tamaño del quiste han aumentado, comprometiendo aproximadamente la circunferencia en $180^{\circ}$ (flecha verde). El control posterior 2 años más tarde muestra nuevamente discreto aumento de tamaño del quiste y del grosor de la pared (flecha azul) y compromiso en $360^{\circ}$. El diagnóstico histopatológico fue adenocarcinoma.

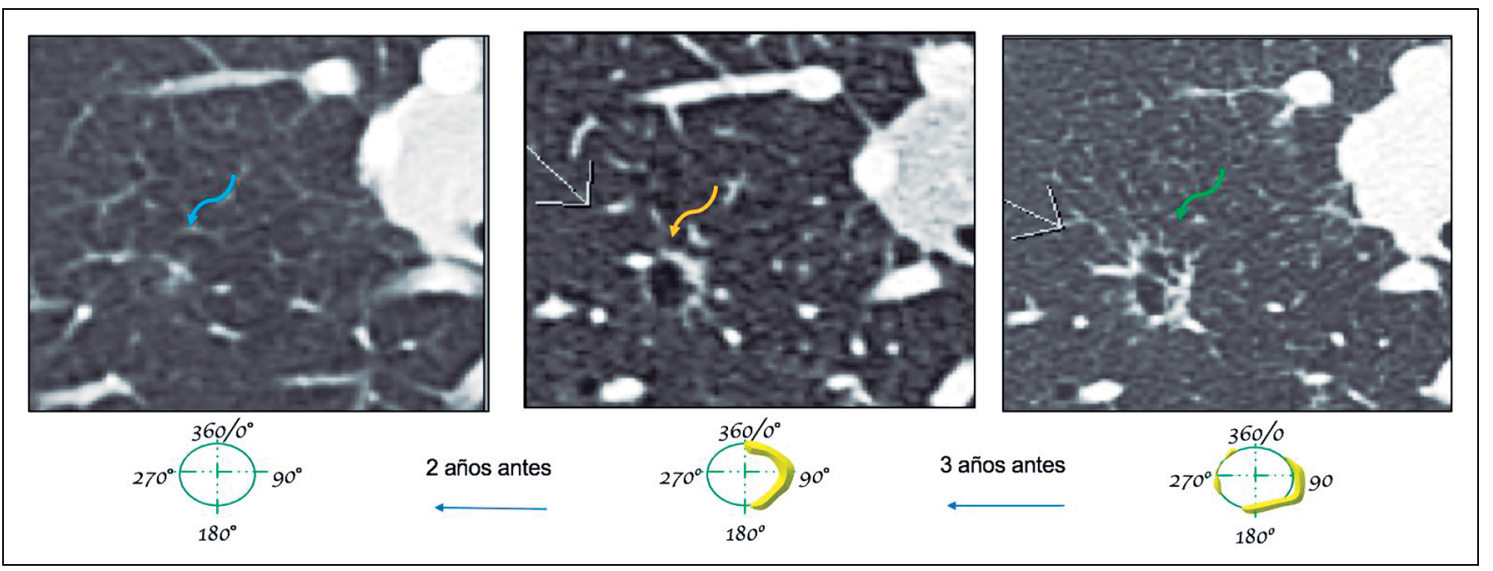

Figura 4. Caso 2. Tipo III. Mujer de 58 años, tabaquismo crónico activo. Se realiza tomografía computada por sospecha de Tromboembolia pulmonar. Se pesquisa lesión quística de pared engrosada y tabiques engrosados en forma irregular (flecha verde). En el análisis retrospectivo de TC previa realizada 3 años atrás (flecha naranja) se observó pequeña formación quística con engrosamiento parcial de su pared $\left(180^{\circ}\right)$. En TC de 5 años atrás (flecha azul) se identificó pequeña opacidad nodular con atenuación en vidrio esmerilado. El diagnóstico histopatológico fue adenocarcinoma.

engrosamiento de su pared en porcentaje variable, dos (Figuras 3 y 4 ) y tipo IV con tabiques internos, uno (Figura 10). La ubicación de la lesión quística correspondió a cuatro subpleurales, tres periféricos y uno central o parenquimatoso. En los seis pacientes en que se realizó más de un control, se observó aumento del diámetro del espacio quísti- co. Las características morfológicas de las lesiones y las alteraciones asociadas se describen en detalle en la Tabla 2.

El tiempo de retardo de diagnóstico fue de 871 días (rango 0-1592) (Tabla 3). En tres pacientes se sospechó lesión neoplásica en el primer examen; los tres correspondieron a lesiones tipo I, con 


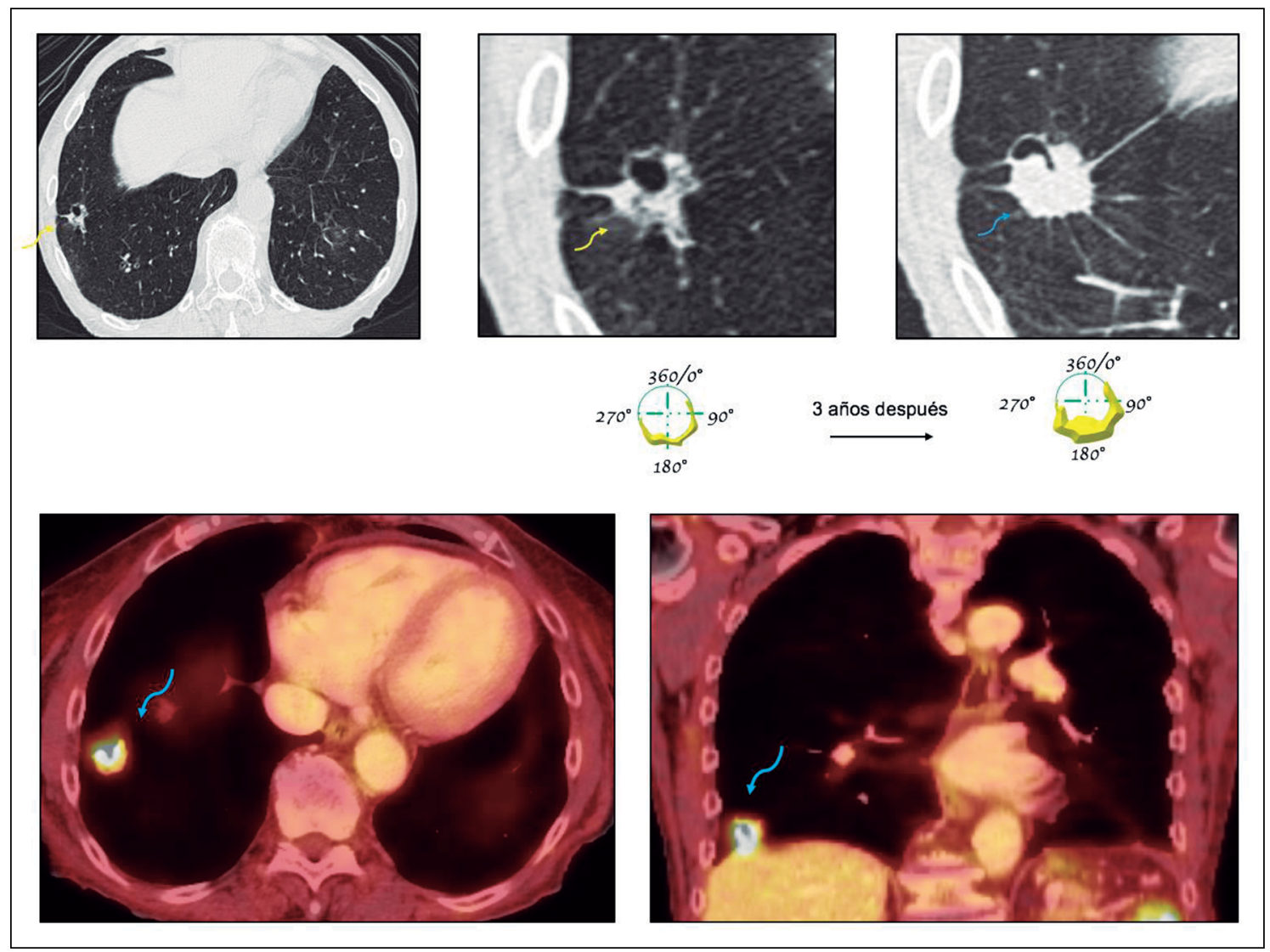

Figura 5. Caso 3. Patrón tipo I. Mujer de 72 años con antecedentes de tabaquismo detenido. En primer estudio se observa quiste pulmonar periférico con tejido de partes blandas que rodeaba en aproximadamente $210^{\circ}$ su borde externo (flecha amarilla). Paciente perdido durante el seguimiento. En control posterior (1.118 días) se observó aumento de densidad y tamaño del tejido blando invadiendo el lumen de la lesión quística (flecha azul), manteniendo el compromiso circunferencial en $210^{\circ}$. El diagnóstico histopatológico fue adenocarcinoma. Imágenes de PET/CT Muestran lesión hipermetabólica pulmonar quística de paredes engrosadas con un SUV Max de 10,3.

Tabla 2. Características morfológicas de los cánceres pulmonares en relación con espacios aéreos quísticos

\begin{tabular}{|c|c|c|c|c|c|c|c|c|c|c|c|c|c|}
\hline & \multicolumn{2}{|c|}{ Tipo } & \multicolumn{2}{|c|}{$\begin{array}{l}\text { Diámetro } \\
\text { quiste } \\
\text { (mm) }\end{array}$} & \multicolumn{2}{|c|}{$\begin{array}{l}\text { Diámetro } \\
\text { nódulo } \\
\text { (mm) }\end{array}$} & \multicolumn{2}{|c|}{$\begin{array}{l}\text { Grosor } \\
\text { pared } \\
(\mathbf{m m})\end{array}$} & \multicolumn{2}{|c|}{$\begin{array}{l}\text { \% pared } \\
\text { compro- } \\
\text { metida }\end{array}$} & \multirow[t]{2}{*}{ Enfisema } & \multicolumn{2}{|c|}{ Ubicación } \\
\hline & Inicial & Final & Inicial & Final & Inicial & Final & Inicial & Final & Inicial & Final & & Lób & $A x$ \\
\hline Paciente 1 & NM & III & NM & 10 & NM & NM & 1 & 5 & 0 & $360^{\circ}$ & Avanzado CL & LII & SP \\
\hline Paciente 2 & III & IV & 3 & 12 & NM & NM & 1 & 3 & 0 & $180^{\circ}$ & Leve CL/PS & LSD & $\mathbb{I P}$ \\
\hline Paciente 3 & 1 & 1 & 11 & 13 & 7 & 15 & 5 & 19 & $210^{\circ}$ & $210^{\circ}$ & Leve CL & LID & $P$ \\
\hline Paciente 4 & 1 & 1 & 7 & 7 & NM & NM & 3 & 3 & $180^{\circ}$ & $180^{\circ}$ & No & LSI & $P$ \\
\hline Paciente 5 & I & NC & 15 & NC & 23 & NC & 7 & NC & $270^{\circ}$ & NC & Leve CL/PS & LII & SP \\
\hline Paciente 6 & $\|$ & $\|$ & 7 & 19 & 3 & 13 & 1 & 3 & $30^{\circ}$ & $180^{\circ}$ & Leve CL & LSI & $P$ \\
\hline Paciente 7 & I & I & 24 & 24 & 24 & 24 & 2 & 3 & $60^{\circ}$ & $60^{\circ}$ & Leve CL & LID & SP \\
\hline Paciente 8 & IV & I & 26 & 45 & NM & 21 & 0 & 8 & $0^{\circ}$ & $180^{\circ}$ & Avanzado CL/PS & LSI & SP \\
\hline
\end{tabular}

Abreviaciones: CL: centrolobulillar. PS: paraseptal. Ax: ubicación en el plano axial. SP: subpleural. IP: intraparenquimatoso.

P: periférico. NM: No medible. NC: No corresponde. 

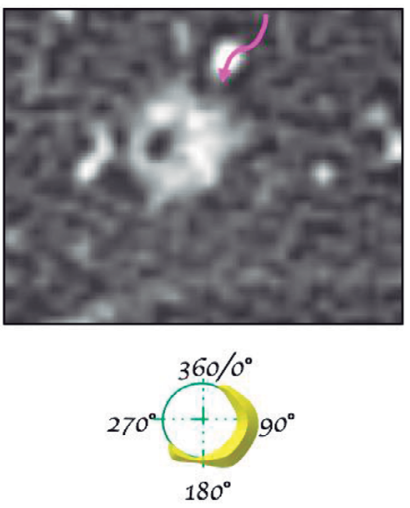

19 meses después
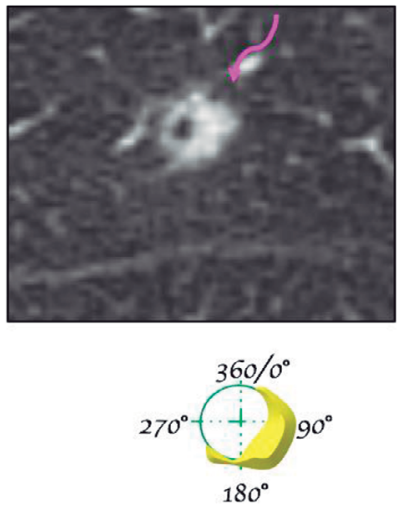

Figura 6. Caso 4. Patrón tipo I, Paciente de sexo femenino de 44 años. Debido a sospecha de tromboembolia pulmonar se solicitó AngioTC de tórax. Se identificó un nódulo quístico tipo I, 7 mm de diámetro, 3 mm de espesor del nódulo con compromiso de la pared en $180^{\circ}$ (flechas rosadas). Diecinueve meses después se mantiene sin variaciones. El diagnóstico histopatológico fue adenocarcinoma.

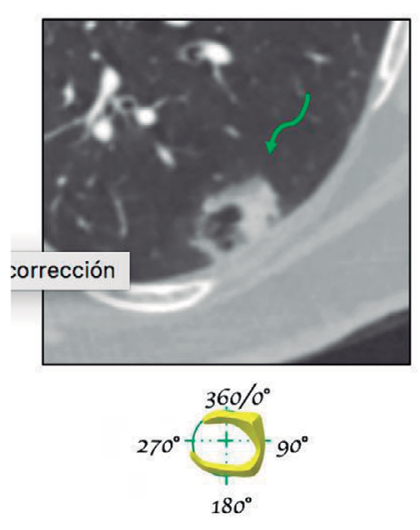

Sin retraso en el diagnóstico
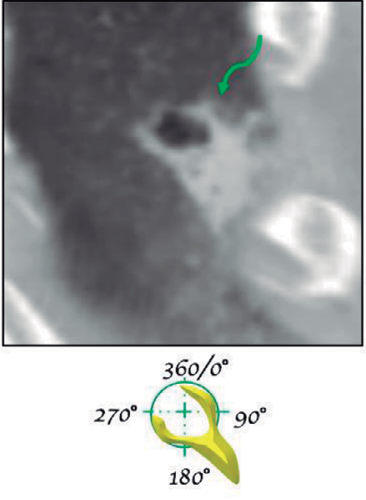

Figura 7. Caso 5. Patrón tipo I. Hombre de 75 años, con antecedente de tabaquismo. Se realiza AngioTC de Tórax para estudio de patología aórtica. Incidentalmente se pesquisa lesión quística con contenido aéreo subpleural, con densidad de partes blandas rodeando la pared externa del espacio quístico. Se sospechó lesión neoplásica en el primer control. El diagnóstico histopatológico fue adenocarcinoma.

Tabla 3. Tipo de informe con respecto a engrosamiento de la pared quística, retardo en el diagnóstico y etapificación

\begin{tabular}{|llcc|}
\hline Paciente & Tipo informe & Retardo en el diagnóstico (días) & Etapificación \\
\hline Paciente 1 & No descrito & 823 & IA \\
\hline Paciente 2 & No descrito & 1.105 & IA \\
\hline Paciente 3 & Benigno & 1.118 & IIA \\
\hline Paciente 4 & Sospechoso & 0 & IA \\
\hline Paciente 5 & Sospechoso & 0 & IB \\
\hline Paciente 6 & No descrito & 921 & NC \\
\hline Paciente 7 & Sospechoso & 0 & IV \\
\hline Paciente 8 & Benigno & 1.592 & \\
\hline
\end{tabular}




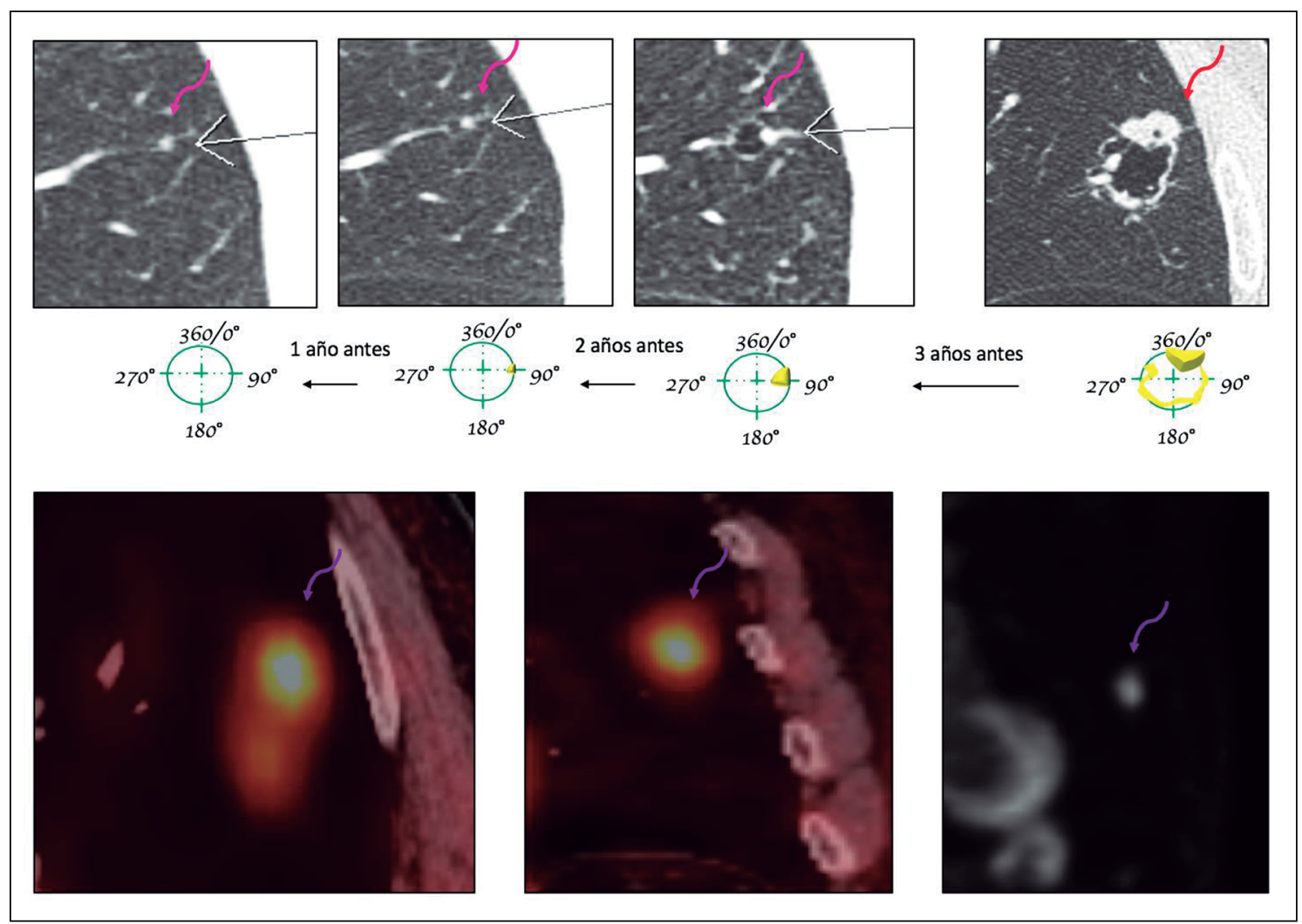

Figura 8. Caso 6. Patrón tipo Il. Hombre de 68 años, tabaquismo detenido, en control por Adenocarcinoma pulmonar operado. En el último control (flecha roja) se informa lesión quística de pared nodular sospechosa de lesión neoplásica. El PET/ CT mostró lesión hipermetabólica (flechas moradas) SUV Max de 6,3. El diagnóstico histopatológico fue Carcinoma escamocelular. El análisis retrospectivo mostró en primer control cuatro años atrás una pequeña densidad nodular menor de 3 mm de diámetro en esa zona, la que en controles al año y dos años se vio confinada por una formación quística de pared fina y contenido aéreo.

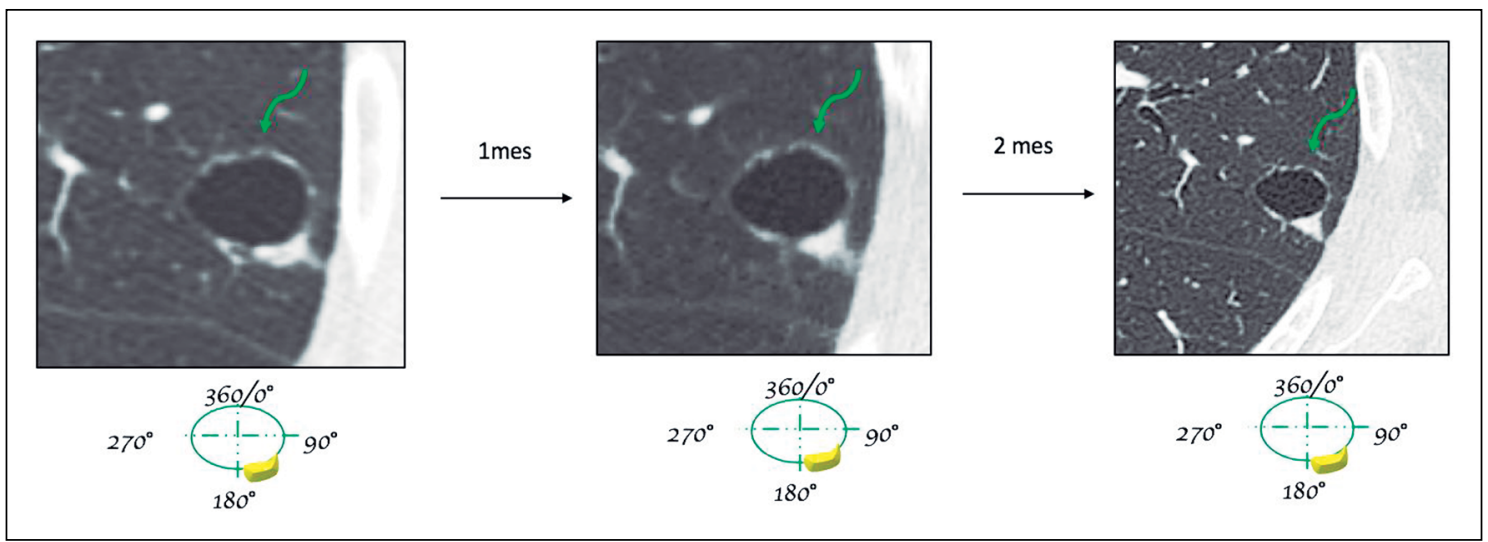

Figura 9. Caso 7. Patrón tipo I. Mujer de 77 años, tabaquismo detenido hace un año. Se realiza tomografía computada por sospecha de neumonia y Rx de tórax anormal. Se pesquisó espacio quístico con contenido aéreo subpleural con densidad de partes blandas de borde espiculado externo a la pared en el lóbulo inferior derecho (flechas verdes). La biopsia transbronquial informó adenocarcinoma. 

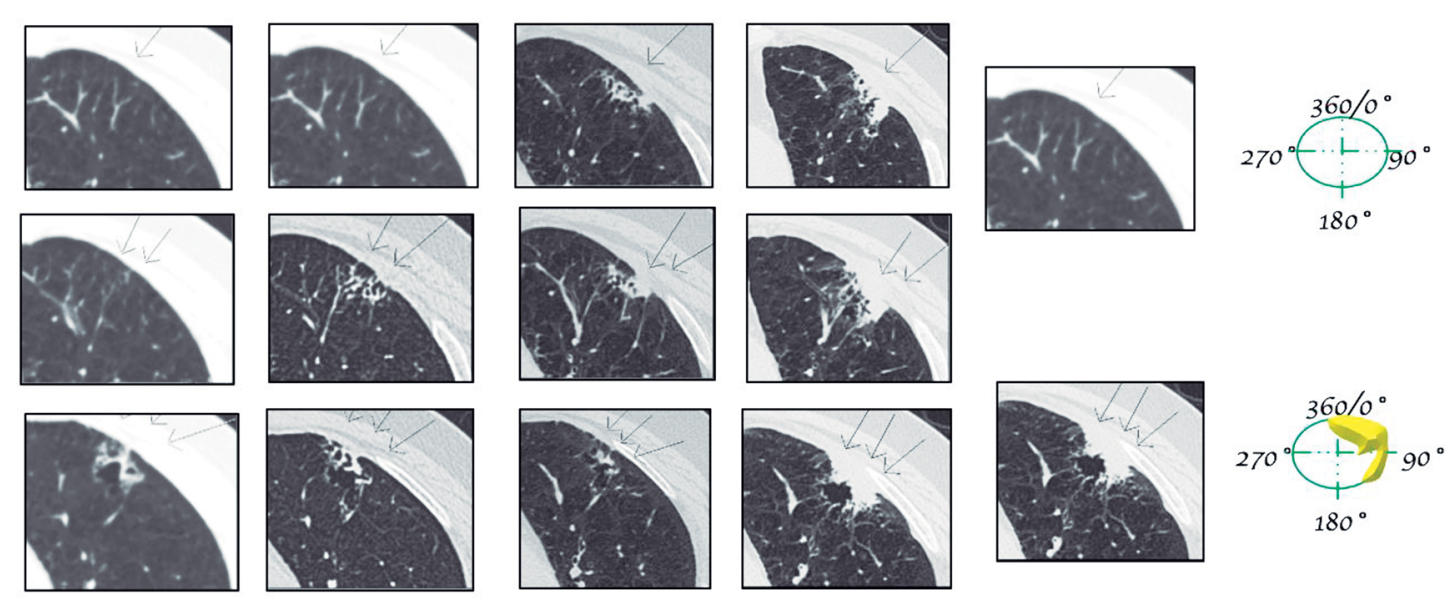

Figura 10. Caso 8. Patrón tipo IV. Hombre de 61 años, tabaquismo crónico activo en control por enfisema. La primera tomografía computada muestra una zona periférica en el lóbulo superior izquierdo conteniendo pequeños quistes con contenido aéreo y pared de grosor irregular. Esta lesión creció progresivamente en los controles posteriores interpretándose como lesión cicatricial. En la última tomografía computada se observa que el componente de partes blandas y grosor de la pared ha aumentado, apareciendo una lesión nodular de contorno espiculado sobresaliendo de la pared de la zona quística. El diagnóstico histopatológico fue adenocarcinoma.

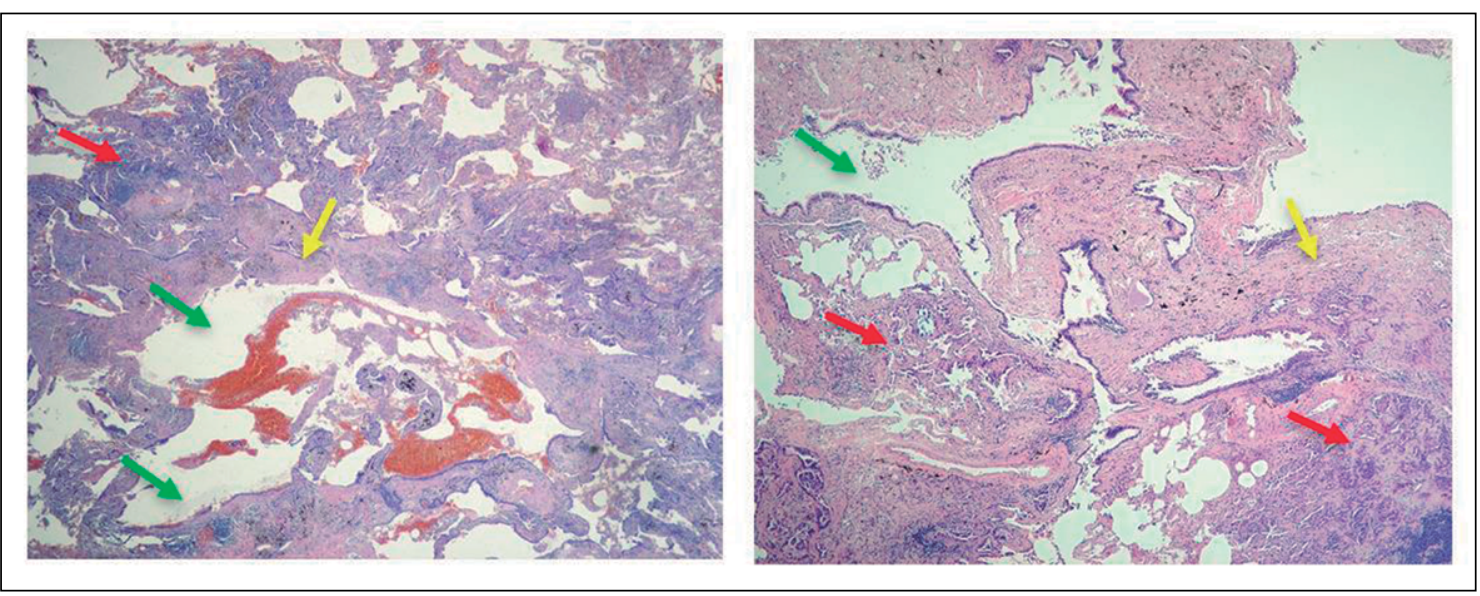

Figura 11. Tinciones Hematoxilina-Eosina, aumento de 10x que demuestran cavidades quísticas (flechas verdes) revestidas por epitelio bronquial normotípico (fechas amarillas) rodeadas por tumor (fechas rojas), con estroma esclerosante y con patrón lepídico y acinar.

nódulos de $23 \mathrm{~mm}, 4 \mathrm{~mm}$ y $24 \mathrm{~mm}$ de diámetro (Figuras 6, 7,9). En los cinco casos restantes hubo retardo en la sospecha de neoplasia. Uno correspondió a lesión quística inicialmente de pared fina, en el cual la aparición de engrosamiento de la pared no fue considerado signo de sospecha, con retardo en el diagnóstico de 823 días (Figura 3), etapa IA. Otros dos correspondieron a lesiones tipo I y IV que inicialmente fueron considerados lesiones benignas (Figuras 5, 10); el retardo en el diagnóstico fue de 1.118 y 1.592 días respectivamente, el primero etapa IIIA y el segundo etapa IV. No fueron descritos en el informe inicial los casos uno, dos y seis (Figuras 3,4,8), porque correspondían a lesiones imperceptibles o confundentes; los dos primeros al momento del diagnóstico se encontraron en estadío IA y el último en estadío IB.

El mayor retraso en el diagnóstico fue de 1.592 
días, del caso del paciente 8 (Figura 10), catalogado inicialmente como hallazgo benigno y en la etapificación correspondió a estadío IV (Tabla 3).

Cinco de los pacientes fueron a PET-CT. En tres no se demostró hipermetabolismo, ambos con grosor de pared de menor a $5 \mathrm{~mm}$ y en los dos que hubo captación severa del trazador (SUV 6,3 y 10), el grosor de sus paredes era de $3 \mathrm{~mm}$ (Figuras 8, 5).

De los 8 pacientes, 7 fueron a resección quirúrgica y en todos ellos estuvieron disponibles las placas histológicas para revisión. En 6 casos, las placas mostraron el tumor pero no el espacio quístico. En sólo un caso se identificó el quiste y correspondió a una estructura bronquial dilatada (Figura 11).

\section{Discusión}

La presentación de cáncer pulmonar en relación a pequeñas formaciones quísticas de contenido aéreo es una manifestación infrecuente. En el programa I-ELCAP correspondió a 3,6\% (26/706) de los cánceres pulmonares detectados ${ }^{3}$, cifra similar a la reportada por Kaneda et al. ${ }^{5}$ en el que se identificó cáncer adosado a una bula en 3,5\% (19/545) . Si bien esta asociación ha sido publicada recientemente ${ }^{2,4,6,7}$, es poco conocida entre los radiólogos, provocando con frecuencia retardo en el diagnóstico. De datos obtenidos del ensayo NELSON, Scholten et al. ${ }^{6}$ reporta que de los 61 carcinomas de intervalo o post screening, el $36 \%(22 / 61)$ ya era visible en un examen previo, pero pasado por alto y el $22 \%$ de ellos (5/22) correspondían a espacios quísticos aéreos con engrosamiento de sus paredes. Mascalchi et $\mathrm{al}^{7}$, reportó una situación similar en el ensayo ItalLung; en 20 cánceres de intervalo, 17, ya mostraban lesiones focales en el examen previo, dos de ellos asociados con quiste de contenido aéreo. En un reporte posterior de 24 pacientes con cáncer pulmonar asociado a espacios quísticos, Mascalchi pone una voz de alerta dado que el $37 \%$ de esos casos fueron diagnosticados en etapas ya avanzadas ${ }^{4}$. En nuestra serie de pacientes, en tres se sospechó lesión neoplásica en el primer examen, todos con engrosamiento evidente de las paredes del quiste, dos nodulares y otro concéntrico. En los restantes cinco, el aumento de grosor de la pared o la presencia de una opacidad de partes blandas en relación a ella no fue considerado signo de sospe- cha inicialmente, con mediana de 872 dias (rango 0-1.592) de retardo en el diagnóstico. En dos de estos cinco pacientes el diagnóstico de cáncer se hizo en etapa ya avanzada, con retardos de 1.152 y 1.592 días.

Se postula para explicar la asociación entre quiste y cáncer pulmonar, que la lesión neoplásica provocaría una obstrucción por mecanismo de válvula a nivel del bronquiolo terminal formándose un quiste por atrapamiento aéreo ${ }^{3}$. En dos de nuestros casos un nódulo sólido y otro subsólido precedieron la aparición de la formación quística (Figuras 4, 8), lo que apoyaría esta hipótesis, así como el hecho de que en otros cuatro pacientes el quiste aumentó de diámetro en el tiempo (Tabla 2).

El comportamiento de estas lesiones en el PET$\mathrm{CT}$, no difiere de la que se observa en los nódulos pulmonares sólidos, de modo que todas aquellas lesiones con pared de grosor menor a $8 \mathrm{~mm}$ es esperable que no presenten captación del trazador.

Una limitante de nuestro estudio es que no tenemos un registro de los pacientes con quistes pulmonares con contenido aéreo que no tuvieron diagnóstico de cáncer pulmonar, de modo que no podemos estimar la frecuencia total con la que estas formaciones quisticas se asocian a cáncer pulmonar. No tenemos certeza del diagnóstico de otras lesiones quísticas potencialmente benignas.

\section{Conclusión}

La presencia de cáncer pulmonar en relación a quistes con contenido aéreo corresponde a una presentación infrecuente y poco conocida entre los radiólogos, lo que puede causar retraso en el diagnóstico definitivo. El elemento que debe hacer sospechar malignidad es el progresivo engrosamiento de la pared de un quiste ya sea difuso o nodular, asociado o no a aumento de su diámetro.

\section{Referencias}

1. Ost DE, Gould MK. Decision making in patients with pulmonary nodules. Am J Respir Crit Care Med 2012; 185 (4): 363-72.

2. Devaraj A. Missed cancers in lung cancer screening more than meets the eye. Eur Radiol 2014;10-2.

3. Farooqi AO, Cham M, Zhang L, Beasley MB, Austin 
JHM, Miller A, et al. Lung cancer associated with cystic airspaces. Am J Roentgenol 2012; 199 (4): 781-6.

4. Mascalchi. Lung cancer associated with cystic airspaces. J Comput Assist Tomogr 2015; 39 : 102-8.

5. Kaneda M, Tarukawa T, Watanabe F, Adachi K, Sakai T. Clinical features of primary lung cancer adjoining pulmonary bulla. Interact Cardiovasc Thorac Surg. 2010; 10: $940-4$.
6. Scholten ET, Horeweg N, de Koning HJ, Vliegenthart R, Oudkerk M, Mali WPTM, et al. Computed tomographic characteristics of interval and post screen carcinomas in lung cancer screening. Eur Radiol 2015; 25 (1): 81-8.

7. Mascalchi M, Picozzi G, Falchini M, Vella A, Diciotti S, Carrozzi L, et al. Initial LDCT appearance of incident lung cancers in the ITALUNG trial. Eur J Radiol 2014; 83 (11): 2080-6. 